\title{
The effects of ingested alcohol on accommodation
}

\author{
R. J. MILLER, RICHARD G. PIGION, and KEVIN D. MARTIN \\ Washington State University, Pullman, Washington
}

\begin{abstract}
To determine the effects of ingested alcohol on accommodation, seven males, aged 21-22 years, had their accommodation assessed under three alcohol dosage conditions (placebo, $0.8 \mathrm{ml} / \mathrm{kg}$, and $1.3 \mathrm{ml} / \mathrm{kg}$ of $95 \%$ ethanol). For each of these conditions, following drinking, static accommodation to near and far targets (viewing distance $=30 \mathrm{~cm}$ and $6 \mathrm{~m}$ ) and dark focus accommodation were measured every $15 \mathrm{~min}$ for $3 \mathrm{~h}$ in the placebo and medium-dosage conditions and for $6 \mathrm{~h}$ in the high-dosage condition. Results showed that dark, near-target, and far-target accommodation all increased with intoxication. Observations regarding the relationship between dark focus and alcohol-induced static accommodation changes were inconclusive, although there was some indication that this relationship increased at the highest intoxication levels. It was concluded that moderate amounts of ingested alcohol produce small, but significant, increases in accommodation.
\end{abstract}

An understanding of the effects of alcohol on accommodation is desirable for various reasons. Further elucidation of the function and limits of accommodation is basic to understanding vision. The physiological mechanisms involved in accommodation and in the effects of alcohol are incompletely understood, and knowledge of the impact of alcohol on such a visual process may clarify some of these mechanisms. Furthermore, an exploration of alcohol's impact on accommodation has applied importance, especially regarding the influence of intoxication on a variety of visual-motor tasks.

A more specific reason for an interest in alcohol effects on accommodation is found in the fact that diplopia (double vision) is one of the frequently reported symptoms of intoxication (e.g., Brecher, Hartman, \& Leonard, 1955; Cohen \& Alpern, 1969; Colson, 1940; Levett \& Karras, 1977; Powell, 1938). Accommodation and vergence interact in complex ways that have been a source of speculation for years (Alpern, 1958; Carroll, 1982; Fincham \& Walton, 1957; Flom, 1955; Miller, 1980; Morgan, 1944, 1968; Toates, 1970, 1972). As several writers have pointed out (e.g., Alpern, 1969; Cohen \& Alpern, 1969; Olge, Martens, \& Dyer, 1967), alcoholinduced heterophorias might be the effect of changes in accommodation, resulting in parallel changes in accommodative vergence.

At present, only incomplete information is available regarding the effects of alcohol on accommodation. Several investigators have reported that alcohol leads to a deterioration of static acuity (e.g., Mortimer, 1963; Newman \& Fletcher, 1941; Newman, Fletcher, \& Abramson, 1942; Perrine, 1973). Others, however, have reported no effect of alcohol on acuity (Adams, 1978;

This research was supported in part by funds provided by the State of Washington Initiative Measure No. 171 for medical and biological research on alcoholism. Requests for reprints should be sent to $R$. J. Miller, 209 Johnson Tower, Department of Psychology, Washington State University, Pullman, WA 99164-4830.
Adams, Brown, Flom, Jones, \& Jampolsky, 1975; Brecher et al., 1955; Colson, 1940; Verriest \& Laplasse, 1965 ). In any case, acuity is only partly determined by accommodation, and is susceptible to retinal eccentricity, luminance, pupil size, exposure duration, target and eye movements, chromatic aberration, contrast, and a variety of motivational variables (e.g., Graham \& Leibowitz, 1972; LeGrand, 1967; Westheimer, 1965, 1981). It is at best an imprecise indicator of accommodation.

Several studies have examined the effects of alcohol on accommodative vergence (e.g., Alpern, 1969, 1972; Brecher et al., 1955; Cohen \& Alpern, 1969; Colson, 1940; McNamee, Piggins, \& Tong, 1981; Ogle et al., 1967; Powell, 1938). The general result of these studies has been that alcohol produces esophoria for far objects and exophoria for near ones. Unfortunately, the degree to which such changes are the result of shifts in accommodation is unknown.

There are at least two aspects of accommodation that may be affected by alcohol. One is static accommodation (accommodation to nonmoving targets). Few attempts have been made to evaluate such an effect. Cohen and Alpern (1969) concluded that alcohol had no meaningful effect, although their subjects showed considerable variability. Powell (1938) also reported the absence of an effect. However, his subjects were all in the age range of 31-35 years, and accommodation amplitude would have begun to decrease significantly. Levett and Karras (1977) reported that alcohol slowed accommodation time, but they did not assess degree of accommodation change.

Another aspect of accommodation that may be affected by alcohol is dark focus (DF). DF refers to accommodation in the absence of an external stimulus, as is the case in total darkness (e.g., Leibowitz, Hennessy, \& Owens, 1975; Leibowitz \& Owens, 1975a, 1975b; Miller, 1978). DF is taken as an estimate of the intermediate resting state of accommodation, which may represent a neuromuscular balance between sympathetic and parasympathetic influences (e.g., Cogan, 1937; Leibowitz, 1976; Leibowitz 
\& Owens, 1978; Melton, Purnell, \& Brecher, 1955; Miller \& LeBeau, 1982; Morgan, 1957; Schober, 1954; Toates, 1970, 1972). DF may be seen as reflecting a basic tonus, affecting accommodation in a variety of visually impoverished stimulus situations (Alpern \& David, 1958; Johnson, 1976; Leibowitz et al., 1975; Leibowitz \& Owens, 1975a, 1975b, 1978; Morgan, 1957). DF may influence accommodation even in the viewing of highly contoured, well-illuminated stimuli (e.g., Johnson, 1976; Leibowitz \& Owens, 1975b).

The literature regarding the influence of alcohol on the autonomic nervous system is large, but there is no widespread agreement regarding consistent differential sympathetic or parasympathetic effects (e.g., Naitoh, 1972). Various autonomically innervated responses (e.g., heart rate, skin conductance/resistance, respiration) have been shown to be influenced by alcohol (e.g., Cameron, Spence, \& Drewery, 1978; Dengerink \& Fagan, 1978; Ludwig \& Stark, 1975), so it is reasonable to suspect that there might be some effect on DF. However, there are no reports of the effects of alcohol on DF in the literature.

The present study was designed to provide systematic data regarding the effects of ingested alcohol on accommodation. Specifically, it was designed for the administration of controlled dosages of alcohol to human subjects, followed by assessments of DF accommodation and static accommodation to near and far targets.

\section{METHOD}

\section{Subjects}

The subjects were seven males, aged $21-22$ years $(m=21.4$ years). All subjects were moderate drinkers, as defined by the volume-variability index of the drinking habits questionnaire of $\mathrm{Ca}$ halan, Cisin, and Crossley (1969; Cahalan \& Cisin, 1968). Limiting the experiment to males avoided sex differences in the absorption and metabolism of alcohol, partly mediated by the menstrual cycle (e.g., Jones \& Jones, 1976). All subjects' weights were within $10 \%$ of desirable weight as defined by Metropolitan Life Insurance Company Tables (Burton, 1976).

Subjects were screened with a Bausch and Lomb Ortho-Rater. All subjects had uncorrected acuity of at least 20/20 (6/6) far and $13 / 13(0.33 / 0.33)$ near in both eyes. No subjects had any lateral phoria outside of the following ranges: $+0.33^{\Delta}$ to $+1.33^{\Delta}$ eso (far); $-3.0^{\Delta}$ to $-6.0^{\circ}$ exo (near): No subject had any measurable vertical phoria. All had fine stereopsis within normal limits and reported no history of visual problems. Each subject was paid $\$ 70$ for completing all sessions. All subjects were volunteers, from whom informed consent was obtained after the nature of the procedures had been fully explained.

\section{Apparatus}

Intoximeter. An Intoximeter (Model Mark IV, Intoximeter, Inc., St. Louis) was used to make all blood alcohol level (\%BAL) estimates. This instrument uses gas chromatography to estimate \%BAL from deep-lung air samples.

Optometer. All accommodation measurements were made with a laser optometer, the design for which is described in several publications (e.g., Hennessy \& Leibowitz, 1970, 1972; Leibowitz \& Hennessy, 1975; Miller, 1978). Briefly, a beam of light from a lowpower laser is reflected from the surface of a slowly revolving drum. Light from this reflected pattern is flashed at irregular intervals for 0.5 -sec periods in the left-eye visual field of the subject, who perceives a spot of red light containing a pattern of dark moving speckles. The speckles' perceived direction of movement is deter- mined by the distance between the drum and the eye and by the eye's refractive state. Accommodation is determined by moving the drum toward and away from the eye until the point of no apparent motion of the speckles is found. Any standard psychophysical technique can be used; in the present study, a staircase procedure (Miller, Pigion, Wesner, \& Patterson, 1983) was adopted.

The subject, secured by a biteboard, viewed the pattern and all other visual stimuli through a Phoroptor. Although its optics were not used in the present study, the Phoroptor provided a convenient means of maintaining head position. Since the biteboard made oral responding difficult, the subject was given a push button connected to a buzzer. With this, he could indicate the perceived direction of movement of the speckle pattern.

Targets. Each target was a black cross on a circular white background. Two targets were used, one for near viewing $(30 \mathrm{~cm}$ from the corneal apex; dioptric equivalent $=3.33$ ) and the other for far (6 m; dioptric equivalent $=0.17$ ). Dimensions of the far cross are shown in Figure 1. Dimensions for the near target were reduced by a factor of 20 . The gap in the one arm of the cross had a visual angle of $2.29^{\prime}$. The white background was $2.41^{\circ}$ in diameter. The remainder of the visual field was black. The average overall luminance of each target was $316 \mathrm{~cd} / \mathrm{m}^{2}$.

Each cross could be turned about its central axis so the gap could be in an up, down, left, or right position. The subject's task was to indicate the position of the gap. Since the gap was very small, accurate performance required constant effort, as the cross was rotated approximately every $5 \mathrm{sec}$. Each new position of the gap was determined randomly. Both targets were aligned directly in front of the subject's left eye. The speckle pattern of the optometer, when exposed, was centered on the cross. All targets were viewed monocularly.

The rotating cross required that reasonably constant attention and accommodation be maintained (as it was necessary for reliable determination of the gap's position), and provided a means for the experimenter to monitor this. Since the biteboard made oral responding difficult, the subject was provided with a video-game "joystick." He indicated the position of the target gap by moving the joystick

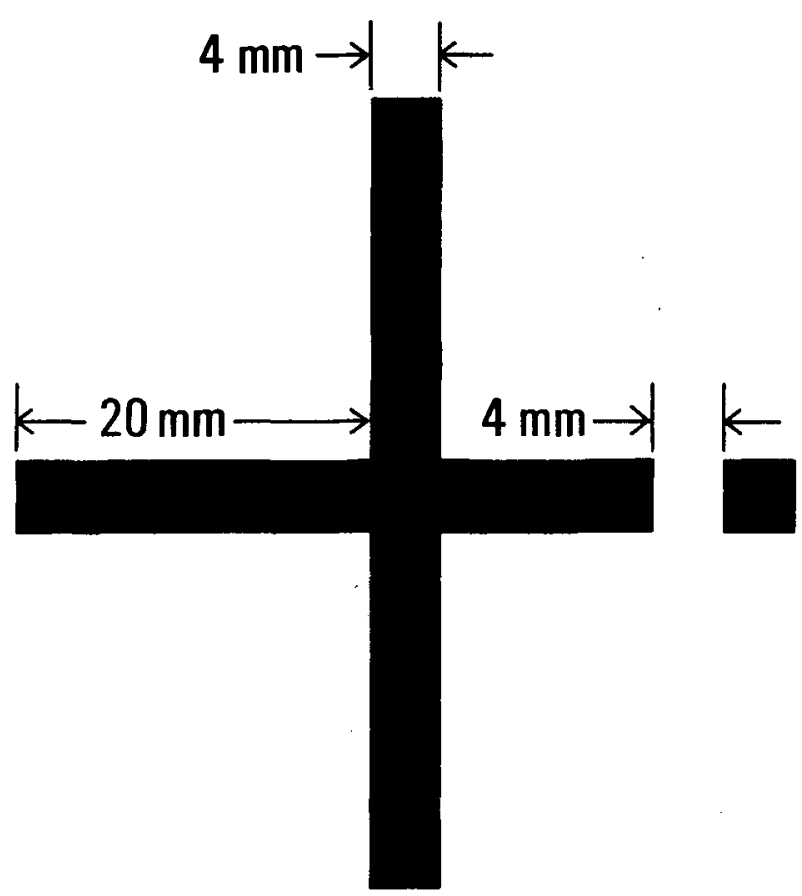

Figure 1. The far target cross and its dimensions. The near target was identical, except that all dimensions were reduced by a factor of $\mathbf{2 0}$. 
in the appropriate direction. The joystick was wired to a panel of lights, visible only to the experimenter, which showed the subject's responses. Errors were rare, and the subject was informed whenever he made an incorrect response.

\section{Procedure}

The experiment consisted of three conditions, each presented during a separate session and differentiated only in terms of alcohol dosage. Each subject experienced all three conditions. All sessions were run in the evening to minimize diurnal variation in alcohol response. Prior to these three sessions, each subject participated in a screening session.

Screening session. The purpose of the screening session was to ascertain that the subject met all criteria for participation and to give practice with the apparatus and procedures. His height and weight were measured, and the drinking habits questionnaire was administered. He was then screened for general visual functioning with the Ortho-Rater. Following these measurements, he practiced detecting the optometer speckle pattern in total darkness and while viewing the near and far targets.

At the end of the screening session, the subject was given instructions to consume no alcohol or other drugs on testing days, and to avoid consumption of any food or liquid (other than water) during the $3 \mathrm{~h}$ preceding each experimental session.

Experimental sessions. The procedures for each of the three experimental sessions were identical except for the dosage of alcohol. For each session, the subject was given $10 \mathrm{ml}$ of total liquid per kilogram of body weight. For the placebo condition, the drink was pure unsweetened tomato juice. For the medium-dosage condition, the drink contained $0.8 \mathrm{ml} / \mathrm{kg}$ of 190 proof (95\%) ethanol mixed with tomato juice. For the high-dosage condition, the drink contained $1.3 \mathrm{ml} / \mathrm{kg}$ of ethanol mixed with tomato juice. Each drink was served in a covered opaque cup and was consumed through a straw. To help disguise the alcohol content, two drops of ethanol and two drops of eucalyptus oil were placed on the cover so that all drinks smelled the same. Each condition for each subject was run on a separate evening. The order of conditions was determined by partial counterbalancing.

At the beginning of each session, baseline values of four variables were assessed, in the following order: (1) blood alcohol level (\%BAL); (2) dark focus (DF; determined in total darkness); (3) near-target accommodation (determined as the subject responded to the near target); and (4) far-target accommodation (determined as he responded to the far target). In the case of DF, actual assessment began approximately $1 \mathrm{~min}$ after the room lights were extinguished.

After these measurements, the subject ate a small amount of food. This consisted of white bread, $0.9 \mathrm{~g} / \mathrm{kg}$ of body weight. The food was given to alleviate the problem of occasional subjects who become nauseous when drinking alcohol on an empty stomach. After the food had been consumed, the subject was given the drink for that session. He was given $20 \mathrm{~min}$ to consume it, with $25 \%$ of it being given every $5 \mathrm{~min}$. Then a 10 -min period elapsed while alcohol remaining in the mouth and throat tissues was absorbed. Toward the end of this period he rinsed his mouth thoroughly with water.

When the 10-min absorption period ended, measurements of \%BAL, DF, near-target accommodation, and far-target accommodation were again made, and were repeated every $15 \mathrm{~min}$. For the placebo and medium-dosage conditions, they were continued for a total of $3 \mathrm{~h}$. For the high-dosage condition, they continued for $6 \mathrm{~h}$.

\section{RESULTS}

\section{Basic Data Regarding \%BAL}

As described earlier, \%BAL was assessed once every 15 min. In all cases, baseline \% BAL was zero. For the seven subjects, the mean peak \%BAL value for the medium dosage condition was $.051(\mathrm{SD}=.013$, range $=.031-.076$ ). The mean peak \% BAL value for the highdosage condition was $.087(\mathrm{SD}=.010$, range $=.079$ .109). The mean number of the time interval during which each subject's peak \%BAL value first occurred was 4.14 for the medium-dosage condition (SD $=1.12$, range $=$ $3-6)$ and 8.14 for the high-dosage condition (SD $=1.96$, range $=6-12$ ).

\section{Baseline Data}

The presence of baseline data made it possible to determine if there were any preexisting differences among the three sessions that could confound the effects of alcohol on accommodation. For purposes of communication, the three levels of alcohol dosage (placebo, medium dosage, and high dosage) will be referred to as "dosage condition," and the three viewing conditions under which accommodation was measured (dark, near target, and far target) will be referred to as "stimulus condition." A $3 \times 3$ (dosage condition $\times$ stimulus condition) analysis of variance was performed on the baseline accommodation data. As would be expected, stimulus condition had a significant effect on accommodation $[\mathrm{F}(2,12)=56.02$, $\mathrm{p}$ $<.0001]$. Dosage condition had no significant effect, and the interaction was not significant.

\section{Control Data}

The purpose of the placebo condition was, of course, to determine if such extraneous variables as subject expectations and such time-related functions as fatigue or stress could confound the alcohol consumption conditions. Accommodation was examined for the placebo condition alone. A $3 \times 13$ (stimulus condition $\times$ time interval) analysis of variance was performed. The 13 time intervals included baseline plus the 12 postdrinking intervals. Stimulus condition was statistically significant $[F(2,12)=$ $45.54, \mathrm{p}<.0001]$. Neither time interval nor the interaction was significant.

Although the placebo condition served as a control for extraneous variables, it covered only 13 time intervals. The high-dosage condition, on the other hand, involved 25 time intervals (baseline plus 24 postdrinking intervals), the last 12 of which had no placebo control. To assess time-related changes in accommodation, a $3 \times 25$ (stimulus condition $\times$ time interval) analysis of variance was conducted for the high-dosage condition alone. The time interval effects were not statistically significant. Thus, it is unlikely that any accommodation changes that occurred during the last 12 time intervals of the high-dosage condition were due to time-related functions such as fatigue, boredom, and so forth.

\section{Alcohol-Related Changes in Accommodation}

The principal question to which the present experiment was addressed was whether accommodation would be affected by intoxication. To address that issue, the mediumand high-dosage conditions were analyzed separately. 
Medium-dosage condition. To examine the effects of intoxication level on accommodation, it was not sufficient simply to examine group changes over time. There were considerable intersubject differences regarding when the peak of the \%BAL curve occurred. Since the subjects did not all peak at the same time, any accommodation effects induced by higher levels of intoxication would be distributed across numerous time intervals when the group was examined as a whole, diluting their effects in any analysis based on time-related changes.

To solve this problem, each subject's accommodation data were divided into three intoxication levels. The first level (BAL 1) consisted only of baseline data. The second level (BAL 2) consisted of the means of all postdrinking data obtained for a given subject when his \%BAl was .025 or less. The third level (BAL 3) consisted of the means of data obtained for the subject when his \%BAL was .026 or greater. This made possible a $3 \times 3$ factorial arrangement of stimulus condition (dark, near target, and far target) $\times$ intoxication level (BAL 1, BAL 2, and BAL 3). The accommodation data for the cells of this design are shown in Figure 2. Analysis of variance showed that the effect of stimulus condition was significant $[F(2,12)=$ $57.28, \mathrm{p}<.0001$ ], as was that of intoxication level $[F(2,12)=14.34, p<.001]$. The interaction was not significant.

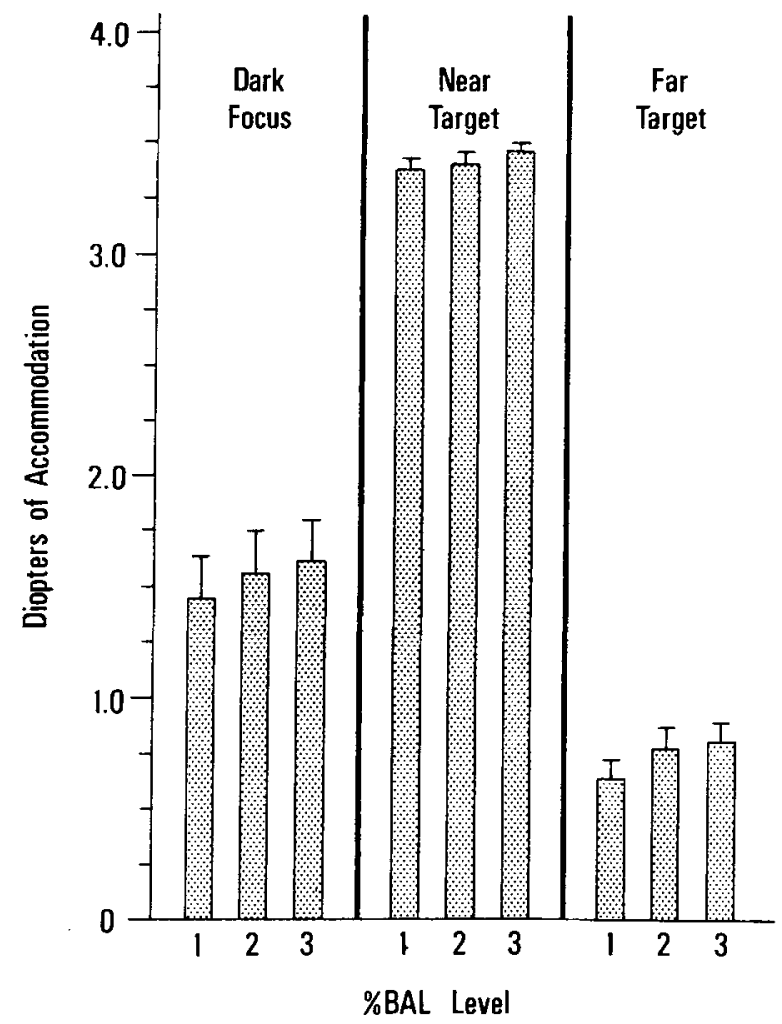

Figure 2. Accommodation as a function of intoxication level for the medium-dosage condition. Variability expressed as standard error of the mean.

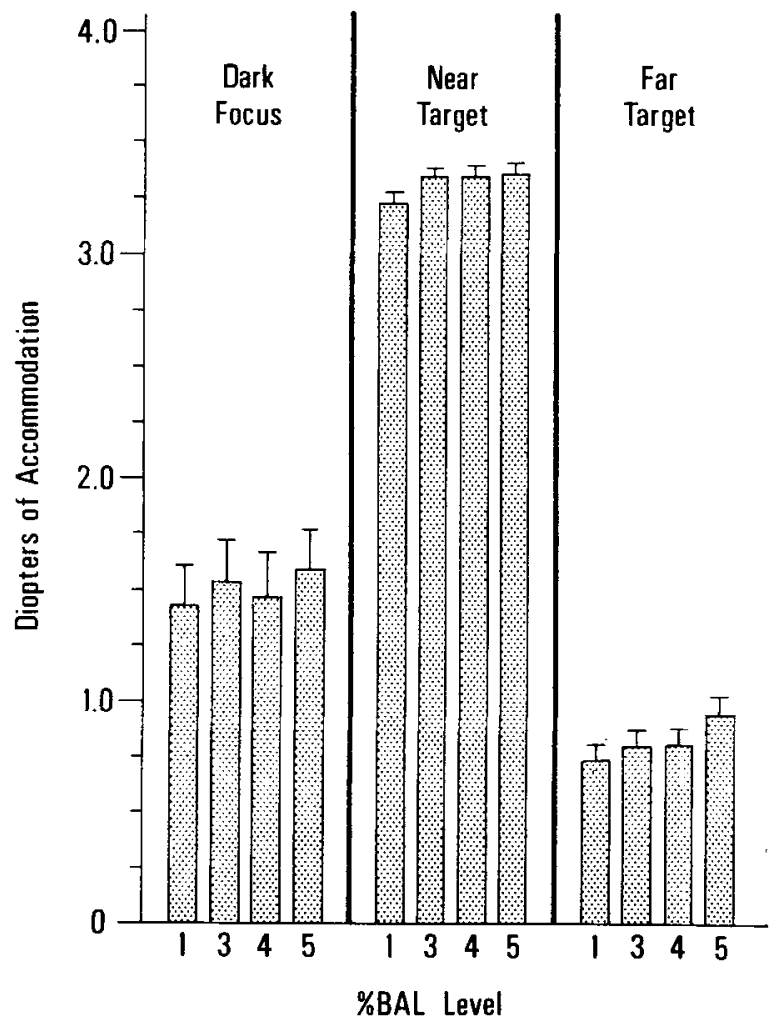

Figure 3. Accommodation as a function of intoxication level for the high-dosage condition. Variability expressed as standard error of the mean.

High-dosage condition. For the high-dosage condition, each subject's data were divided into four intoxication levels. The first level (BAL 1) consisted only of baseline data. The second level (BAL 3) consisted of the means of all postdrinking accommodation data obtained for each subject when his \%BAL was .026-.050. The third level (BAL 4) consisted of the means of data for each subject when his \%BAL was .051-.075. The fourth level (BAL 5) consisted of the means of data for each subject when his \%BAL was .076 and above. For the high-dosage condition, there was no level corresponding to \% BAL between zero and .026 because in most cases \% BAL rose rapidly enough after drinking that it already had passed this range when measurements began and had not dropped back into this range by the time the $6 \mathrm{~h}$ of measurements had terminated.

The resulting four intoxication levels created a $3 \times 4$ factorial arrangement of stimulus condition (dark, near target, far target) $\times$ level of intoxication (BAL 1, BAL 3, BAL 4, BAL 5). The accommodation data for the cells of this design are shown in Figure 3. A $3 \times 4$ analysis of variance was performed on these data. The effect of stimulus condition was statistically significant $[\mathrm{F}(2,12)=$ $51.47, \mathrm{p}<.0001]$, as was the effect of intoxication level $[F(3,18)=4.40, p=.017]$. The interaction was not significant. 
Table 1

Accommodation Change Scores for Medium- and High-Dosage Conditions

\begin{tabular}{|c|c|c|c|c|c|c|}
\hline \multirow{3}{*}{$\begin{array}{l}\text { Intoxication } \\
\text { Level } \\
\end{array}$} & \multicolumn{6}{|c|}{ Stimulus Condition } \\
\hline & \multicolumn{2}{|c|}{ Dark } & \multicolumn{2}{|c|}{ Near Target } & \multicolumn{2}{|c|}{ Far Target } \\
\hline & $\mathbf{M}$ & SD & $\mathbf{M}$ & SD & $\mathbf{M}$ & SD \\
\hline \multicolumn{7}{|c|}{ Medium Dosage Condition } \\
\hline BAL 2 & 0.12 & 0.15 & 0.02 & 0.08 & 0.14 & 0.15 \\
\hline BAL 3 & 0.18 & 0.20 & 0.07 & 0.08 & 0.17 & 0.11 \\
\hline \multicolumn{7}{|c|}{ High Dosage Condition } \\
\hline GAL 3 & 0.10 & 0.28 & 0.12 & 0.18 & 0.07 & 0.17 \\
\hline BAL 4 & 0.03 & 0.38 & 0.13 & 0.23 & 0.08 & 0.17 \\
\hline BAL 5 & 0.16 & 0.21 & 0.14 & 0.16 & 0.20 & 0.20 \\
\hline
\end{tabular}

Table 2

Correlations Between Dark Focus and Accommodation Change Scores for Medium-Dosage Condition

Stimulus Condition From Which

\begin{tabular}{|c|c|c|c|c|c|c|}
\hline \multirow{3}{*}{$\begin{array}{c}\text { Intoxication Level } \\
\text { At Which Dark } \\
\text { Focus Assessed }\end{array}$} & \multicolumn{6}{|c|}{$\begin{array}{l}\text { Stimulus Condition From Which } \\
\text { Change Scores Were Obtained }\end{array}$} \\
\hline & \multicolumn{2}{|c|}{ Dark } & \multicolumn{2}{|c|}{ Near Target } & \multicolumn{2}{|c|}{ Far Target } \\
\hline & BAL 2 & BAL 3 & BAL 2 & BAL 3 & BAL 2 & BAL 3 \\
\hline BAL 1* & -.085 & -.079 & .377 & & .056 & -.144 \\
\hline & & & .3 & & & \\
\hline & .069 & .119 & .344 & -.180 & .083 & -.084 \\
\hline
\end{tabular}

*Baseline

\section{Relation Between Dark Focus and Accommodation Changes}

The previous analyses showed a small, but reliable, tendency for accommodation to increase with intoxication. An important question relates to the degree to which such changes in accommodation are related to each subject's basic (i.e., predrinking) DF.

To evaluate this question, accommodation change values were derived. Accommodation change was defined as the difference between the amount of accommodation observed under a particular intoxication level and the corresponding baseline value. Thus, for example, a given subject's far-target accommodation change for an intoxication level of BAL 5 was found by first taking the mean accommodation value obtained while that subject looked at the far target under BAL 5, and subtracting from it his baseline far-target accommodation value for the high- dosage condition. This procedure defined the amount each subject's accommodation values increased over baseline for each combination of stimulus condition and intoxication level. The means of these accommodation change scores are shown in Table 1.

Medium-dosage condition. The relationship between these change scores and DF was explored by determining, for the seven subjects as a group, the correlations between each of three DF measurements (i.e., for BAL 1 , BAL 2, and BAL 3) and the accommodation change scores. The resulting Pearson product-moment correlation coefficients are shown in Table 2. The correlations between baseline DF (i.e., from BAL 1) and accommodation change are of greatest interest, since baseline DF was measured before drinking and should be most representative of each subject's usual DF. As can be seen in Table 2, none of the correlations was very large and none was statistically significant. It is clear that DF did not significantly influence the degree to which alcohol affected accommodation in the medium-dosage condition.

High-dosage condition. Correlation coefficients obtained for the high-dosage condition are shown in Table 3. Again, the correlations with baseline DF (i.e., BAL 1) are of greatest interest. There was one significant correlation with baseline DF, namely that for accommodation change observed during far-target viewing at BAL 5 . Under these conditions, there was a significant tendency for subjects with higher degrees of DF to show larger accommodation increases. This relationship tended to be significant for the other DF assessments as well.

\section{Effects of Alcohol on the Relationship Between DF and Static Accommodation}

It is known that even under normal viewing conditions DF is related to static accommodation (e.g., Johnson, 1976; Leibowitz \& Owens, 1975b). Subjects with high DF values tend to show higher degrees of accommodation when viewing targets at various distances than do subjects with lower DF values. A question of interest is whether alcohol changes this relationship. Accordingly, correlations were examined between the various DF values obtained in the present experiment and the accommodation values found for both near- and far-target stimulus conditions. The resulting Pearson rs are shown in Ta-

Table 3

Correlations Between DF and Accommodation Change Scores for the High-Dosage Condition

\begin{tabular}{|c|c|c|c|c|c|c|c|c|c|}
\hline \multirow{3}{*}{$\begin{array}{l}\text { Intoxication Level } \\
\text { When DF } \\
\text { Was Assessed }\end{array}$} & \multicolumn{9}{|c|}{ Stimulus Condition From Which Change Scores Were Obtained } \\
\hline & \multicolumn{3}{|c|}{ Dark } & \multicolumn{3}{|c|}{ Near Target } & \multicolumn{3}{|c|}{ Far Target } \\
\hline & BAL 3 & BAL 4 & BAL 5 & BAL 3 & BAL 4 & BAL 5 & BAL 3 & BAL 4 & BAL 5 \\
\hline $\begin{array}{c}\text { BAL 1* } \\
\text { (baseline) } \\
\text { BAL 3 } \\
\text { BAL 4 } \\
\text { BAL 5 }\end{array}$ & $\begin{array}{r}-.148 \\
.135 \\
.230 \\
.061\end{array}$ & $\begin{array}{r}-.076 \\
.205 \\
.300 \\
.134\end{array}$ & $\begin{array}{r}-.170 \\
.102 \\
.197 \\
.046\end{array}$ & $\begin{array}{l}-.214 \\
-.154 \\
-.114 \\
-.180\end{array}$ & $\begin{array}{r}-.057 \\
.017 \\
.061 \\
.007\end{array}$ & $\begin{array}{l}.001 \\
.113 \\
.169 \\
.094\end{array}$ & $\begin{array}{l}.392 \\
.452 \\
.452 \\
.455\end{array}$ & $\begin{array}{l}.316 \\
.324 \\
.320 \\
.348\end{array}$ & $\begin{array}{l}.764^{* *} \\
.768^{* *} \\
.742 \\
.779^{* *}\end{array}$ \\
\hline
\end{tabular}


Table 4

Correlations Between Dark Focus and Static

Accommodation for Medium-Dosage Condition

\begin{tabular}{|c|c|c|c|c|c|c|}
\hline \multirow{3}{*}{$\begin{array}{l}\text { Intoxication Level At } \\
\text { Which Dark Focus } \\
\text { Was Assessed }\end{array}$} & \multicolumn{6}{|c|}{$\begin{array}{l}\text { Stimulus Condition From Which Static } \\
\text { Accommodation Values Were Obtained }\end{array}$} \\
\hline & \multicolumn{3}{|c|}{ Near Target } & \multicolumn{3}{|c|}{$\begin{array}{l}\text { Far Target } \\
\end{array}$} \\
\hline & BAL 1 & BAL 2 & BAL 3 & BAL 1 & BAL 2 & BAL 3 \\
\hline $\begin{array}{l}\text { BAL 1 } \\
\text { BAL 2 } \\
\text { BAL 3 } \\
\end{array}$ & $\begin{array}{l}.557 \\
.583 \\
.607 \\
\end{array}$ & $\begin{array}{l}.670^{*} \\
.678^{*} \\
.70{ }^{*} \\
\end{array}$ & $\begin{array}{l}.665 \\
.688^{*} \\
.722^{*} \\
\end{array}$ & $\begin{array}{l}.757^{* *} \\
.693^{*} \\
.692^{*} \\
\end{array}$ & $\begin{array}{l}.697^{*} \\
.636 \\
.644 \\
\end{array}$ & $\begin{array}{l}.724^{*} \\
.681^{*} \\
.674^{*} \\
\end{array}$ \\
\hline
\end{tabular}

Table 5

Correlations Between Dark Focus and Static Accommodation for High-Dosage Condition

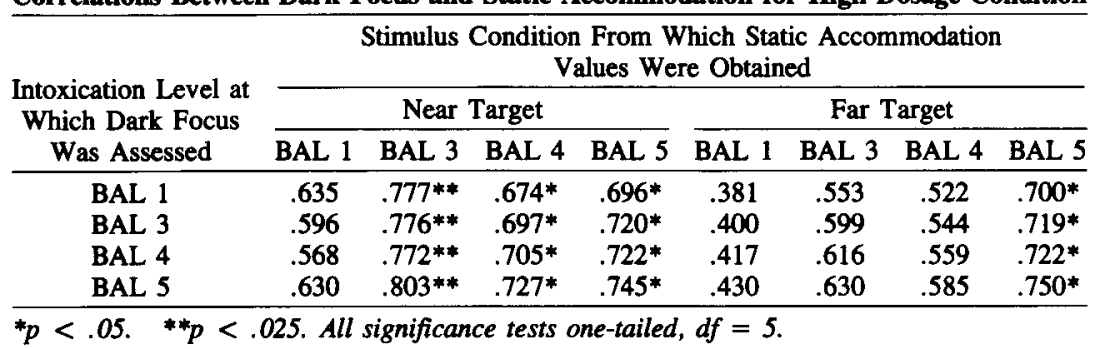

bles 4 and 5. Higher intoxication levels tended to produce correlation coefficients somewhat higher than was the case at baseline.

\section{Ascending Versus Descending \%BAL Curves}

For some tasks, performance while \%BAL is rising is different from that while it is falling (e.g., Fregly, Bergstedt, \& Graybiel, 1967; Hurst \& Bagley, 1972; Jones, 1973). To examine such differences in the present study, ascending curve values for accommodation were compared with descending curve values. Such comparisons were possible only in the high-dosage condition. For the medium-dosage condition, too few values were available on the ascending curves.

A given subject's ascending-curve data consisted of the mean of all his accommodation values (for each stimulus condition) measured during the time intervals preceding that in which his \%BAL first was recorded as .076 or

Table 6

Ascending Versus Decending \%BAL Curve Data For for the High-Dosage Condition

\begin{tabular}{|c|c|c|c|c|c|}
\hline \multirow[b]{3}{*}{ Stimulus Condition } & \multicolumn{4}{|c|}{ Curve Position } & \multirow[b]{3}{*}{ Total $\mathrm{M}$} \\
\hline & \multicolumn{2}{|c|}{ Ascending } & \multicolumn{2}{|c|}{ Descending } & \\
\hline & $\mathbf{M}$ & SD & $\mathbf{M}$ & SD & \\
\hline \multicolumn{6}{|c|}{ Accommodation $*$} \\
\hline $\begin{array}{l}\text { Dark } \\
\text { Near Target } \\
\text { Far Target }\end{array}$ & $\begin{array}{l}1.47 \\
3.31 \\
0.83\end{array}$ & $\begin{array}{l}0.90 \\
0.28 \\
0.29\end{array}$ & $\begin{array}{l}1.54 \\
3.37 \\
0.86\end{array}$ & $\begin{array}{l}1.02 \\
0.25 \\
0.41\end{array}$ & $\begin{array}{l}.151 \\
3.34 \\
0.85\end{array}$ \\
\hline Total & 1.87 & & 1.92 & & \\
\hline \multicolumn{6}{|c|}{ \%BAL } \\
\hline & .062 & 0.01 & .064 & 0.01 & \\
\hline
\end{tabular}

*Accommodation means expressed in diopters. above. Descending-curve data consisted of the means of all his accommodation values measured during the time intervals between that in which his \%BAL last equaled .076 or above and that in which his \%BAL dropped to a level below what it had been in the first postdrinking time interval of the session. The last adjustment was necessary to ensure reasonably symmetrical curves. The group means of these data are shown in Table 6 . A $2 \times 3$ (curve position $\times$ stimulus condition) analysis of variance showed stimulus condition to be significant $[\mathrm{F}(2,12)=$ $53.24, p<.0001]$. Neither the effect of curve position nor the interaction was significant. Thus, the ascendingcurve accommodation values were essentially the same as those for the descending curve.

\section{DISCUSSION}

The most important question was whether alcohol affects accommodation. The data make it clear that it does. There was a small, but reliable, tendency for accommodation to increase as subjects became intoxicated. This was true for both dosages used, and for DF and near and far static accommodation, and was independent of whether the \%BAL curve was ascending or descending. The effects of such changes on everyday vision require further investigation, but it would appear that alcohol-induced accommodation changes should be added to the list of potential factors in the reduced visual-motor performance often resulting from intoxication. Analysis of control conditions showed that it is unlikely that these effects were due to extraneous variables or time-related factors.

What is less clear is the role that DF plays in these effects. With low intoxication levels, it would appear that alcohol effects on accommodation are relatively indepen- 
dent of DF. However, with the highest intoxication level, it appeared that there was a positive relationship between DF and the degree to which accommodation was affected by alcohol, particularly for far-target viewing. Indeed, there was a tendency for the correlations between DF and all aspects of accommodation to increase with intoxication. The highest intoxication levels obtained actually were rather moderate in terms of real-life experience, rarely exceeding the $.10 \%$ limit many states use for motor vehicle operation. The relationship between DF and alcoholinduced accommodation change merits additional research with higher intoxication levels.

Additional research probably also should include an examination of the effects of alcohol on even closer neartarget viewing. The $30-\mathrm{cm}$ distance for the near target in the present experiment was chosen because it is a fair approximation of working distance for many real-life tasks (e.g., reading, product inspection, etc.). However, a target at such a distance certainly does not push accommodation to its limit, particularly for young observers. It would be interesting to know if alcohol shows effects on static accommodation at the near point that are different from those shown in the present study.

\section{REFERENCES}

ADAmS, A. J. (1978). Acute effects of alcohol and marijuana on vision. In S. J. Cool \& E. L. Smith (Eds.), Frontiers in visual science (pp. 93105). New York: Springer-Verlag.

Adams, A. J., Brown, B., Flom, M. C., Jones, R. T., \& JamPOLSKY, A. (1975). Alcohol and marijuana effects on static visual acuity. American Joumal of Optometry and Physiological Optics, 52, 729-735.

ALPERN, M. (1958). Vergence and accommodation: II. Is accommodative vergence related merely to the accommodation stimulus? Archives of Ophthalmology, 60, 358-360.

ALPERN, M. (1969). Types of movement. In H. Davson (Ed.), The eye: Vol. 3. Muscular mechanisms (2nd ed., pp. 65-174). New York: Academic Press.

ALPERN, M. (1972), Effector mechanisms in vision. In J. W. Kling \& L. A. Riggs (Eds.), Woodworth and Schlosberg's experimental psychology: Vol. 1. Sensation and perception (3rd ed., pp. 369-394). New York: Holt, Rinehart \& Winston.

ALPERN, M., DAVID, H. (1958). Effects of illuminance quantity on accommodation of the eyes. Industrial Medicine and Surgery, 72, 551-555.

Brecher, G. A., Hartman, A. P., \& Leonard, D. D. (1955). Effect of alcohol on binocular vision. American Journal of Ophthalmology, 39(2, Pt. II), 44-52.

Burton, B. T. (1976). Human nutrition (3rd ed.). New York: McGraw-Hill.

Cahalan, D., \& Cisin, I. H. (1968). American drinking practices: Summary of findings from a national probability sample. II. Measurement of massed versus spaced drinking. Quarterly Journal of Studies on Alcohol, 29, 642-656.

Cahalan, D., Cisin, I. H., \& Crossley, H. M. (1969). American drinking practices: A national study of drinking behavior and attitudes. New Brunswick, NJ: Rutgers Center of Alcohol Studies.

Cameron, D., Spence, M. T., \& Drewery, J. (1978). Rate of onset of drunkenness: A preliminary study. Journal of Studies on Alcohol, 39, 517-524.

Carroll, J. P. (1982). Control theory approach to accommodation and vergence. American Joumal of Optometry and Physiological Optics, 59, 658-669.

CogAN, D. G. (1937). Accommodation and the autonomic nervous system. Archives of Ophthalmology, 18, 739-766.
COHEN, M. M., \& AL.PERN, M. (1969). Vergence and accommodation: VI. The influence of ethanol on the AC/A ratio. Archives of Ophthalmology, 81, 518-525.

Colson, Z. W. (1940). The effect of alcohol on vision: An experimental investigation. Joumal of the American Medical Association, 115, 1525-1527.

Dengerink, H. A., \& Fagan, N. J. (1978). The effect of alcohol on emotional responses to stress. Journal of Studies on Alcohol, 39, 525-539.

Fincham, E. F., \& Walton, J. (1957). The reciprocal actions of accommodation and convergence. Joumal of Physiology, 137, 488-508.

FLom, M. C. (1955). Variations in convergence and accommodation induced by successive spherical lens additions with distance fixation. American Journal of Optometry and Archives of American Academy of Optometry, 32, 111-136.

Fregly, A. R., Bergstedt, M., \& Graybiel, A. (1967). Relationship between blood alcohol, positional alcohol nystagmus and postural equilibrium. Quarterly Journal of Studies on Alcohol, 28, 11-21.

Graham, C., \& Leibowitz, H. W. (1972). The effect of suggestion on visual acuity. International Joumal of Clinical and Experimental Hypnosis, 20, 169-186.

Hennessy, R. T., \& Leibowitz, H. W. (1970). Subjective measurement of accommodation with laser light. Journal of the Optical Society of America, 60, 1700-1701.

HENNESSY, R. T., \& Leibowitz, H. W. (1972). Laser optometer incorporating the Badal principle. Behavior Research Methods \& Instrumentation, 4, 237-239.

Hurst, P. M., \& Bagley, S. K. (1972). Acute adaptation to the effects of alcohol. Quarterly Journal of Studies on Alcohol, 33, 358-378.

JoHNSON, C. A. (1976). Effects of luminance and stimulus distance on accommodation and visual resolution. Journal of the Optical Society of America, 66, 138-142.

JoNEs, B. M. (1973). Memory impairment on the ascending and descending limbs of the blood alcohol curve. Journal of Abnormal Psychology, 82, 24-32.

JONES, B. M., \& JoNEs, M. K. (1976). Women and alcohol: Intoxication, metabolism, and the menstrual cycle. In M. Greenblatt \& M. A. Schuckit (Eds.), Alcoholism problems in women and children (pp. 103136). New York: Grune \& Stratton.

LeGrand, Y. (1967). Form and space perception (rev. ed., M. Millodot \& G. G. Heath, Trans.). Bloomington: Indiana University Press.

Leibowitz, H. W. (1976). Visual perception and stress. In G. Borg (Ed.), Physical work and effort (pp. 25-37). New York: Pergamon.

Leibowitz, H. W., \& Hennessy, R. T. (1975). The laser optometer and some implications for behavioral research. American Psychologist, 30, 349-352.

Leibowitz, H. W., Hennessy, R. T., \& OWens, D. A. (1975). The intermediate resting position of accommodation and some implications for space perception. Psychologia, 18, 162-170.

LeIBowITZ, H. W., \& OWENs, D. A. (1975a). Anomalous myopias and the intermediate dark focus of accommodation. Science, 189, 646-648.

Leibowitz, H. W., \& OWens, D. A. (1975b). Night myopia and the intermediate dark focus of accommodation. Journal of the Optical Society of America, 65, 1121-1128.

Leibowitz, H. W., \& OWENS, D. A. (1978). New evidence for the intermediate position of relaxed accommodation. Documenta Ophthalmologica, 46, 133-147.

LEVETT, J., \& KaRRAS, L. (1977). Effects of alcohol on human accommodation. Aviation, Space, and Environmental Medicine, 48, 434-437.

LUdWig, A. M., \& StARK, L. H. (1975). "Arousal" and alcoholism: Psychophysiological responses to alcohol. In M. M. Gross (Ed.), Alcohol intoxication and withdrawal (pp. 515-536). New York: Plenum.

McNamee, J. E., Piggins, D., \& Tong, J. (1981). Confirmation of the influence of alcohol on heterophoria using a vision screener. American Journal of Optometry and Physiological Optics, 58, 761-765.

Melton, C. E., Purnell, E. W., \& Brecher, G. A. (1955). The effect of sympathetic nerve impulses on the ciliary muscle. American Journal of Ophthalmology, 40. 155-162.

Miller. R. J. (1978). Mood changes and the dark focus of accommodation. Perception \& Psychophysics, 24, 437-443.

Mille R, R. J. (1980). Ocular vergence-induced accommodation and its relation to dark focus. Perception \& Psychophysics, 28, 125-132. 
Miller, R. J., \& LeBEAU, R. C. (1982). Induced stress, situationallyspecific trait anxiety, and dark focus. Psychophysiology, 19, 260-265.

Miller, R. J., Pigion, R. G., Wesner, M. F., Patterson, J. G. (1983). Accommodation fatigue and dark focus: The effects of accommodation-free visual work as assessed by two psychophysical methods. Perception \& Psychophysics, 34, 532-540.

MORGAN, M. W. (1944). Accommodation and its relationship to convergence. American Journal of Optometry and Archives of American Academy of Optometry, 21, 183-195.

MoRgan, M. W. (1957). The resting state of accommodation. American Journal of Optometry and Archives of American Academy of Optometry, 34, 347-353.

Morgan, M. W. (1968). Accommodation and vergence. American Journal of Optometry and Archives of American Academy of Optometry, 45, 417-454.

MorTimer, R. G. (1963). Effect of low blood-alcohol concentrations in simulated day and night driving. Perceptual \& Motor Skills, 17 399-408.

NAITOH, P. (1972). The effect of alcohol on the autonomic nervous system of humans: Psychophysiological approach. In B. Kissin \& H. Begleiter (Eds.), The biology of alcoholism: Vol. 2. Physiology and behavior (pp. 367-433). New York: Plenum.

Newman, H., \& Fletcher, E. (1941). The effect of alcohol on vision. American Journal of the Medical Sciences 202, 723-731.

Newman, H., Fletcher, E., \& Abramson, M. (1942). Alcohol and driving. Quarterly Journal of Studies on Alcohol, 3, 15-30.

Ogle, K. N., Martens, T. G., \& Dyer, J. A. (1967). Oculomotor imbalance in binocular vision and fixation disparity. Philadelphia: Lea \& Febiger.

PerRine, M. W. (1973). Alcohol influences on driving related behavior: A cricital review of laboratory studies of neurophysiological, neuromuscular, and sensory activity. Journal of Safety Research, $\mathbf{5}$, $165-184$

POWELl, W. H. (1938). Ocular manifestations of alcohol and a consideration of individual variations in seven cases studied. Joumal of Aviation Medicine, 9, 97-103.

SCHOBER, H. (1954). On the resting position of accommodation. Op$t i k, 11,282-290$.

ToAtes, F. M. (1970). A model of accommodation. Vision Research, 10, 1069-1076.

Tontes, F. M. (1972). Accommodation function of the human eye. Physiological Reviews, 52, 828-863.

VerRIEST, G., \& LAPLASSE, D. (1965). New data concerning the influence of ethyl alcohol on human visual thresholds. Experimental Eye Research, 4, 95-101.

WESTHEIMER, G. (1965). Visual acuity. Annual Review of Psychology, 16, 359-380.

Westheimer, G. (1981). Visual acuity. In R. A. Moses (Ed.), Adler's physiology of the eye: Clinical application (7th ed., pp. 530-544). St. Louis: Mosby.

(Manuscript received August 22, 1984; revision accepted for publication March 10, 1985.) 